differentiating between interventions of more clinical relevance as well as intensity would not only elicit more interesting results, but independent of this model, would be more relevant to practice.

The second of these is not a surprise. Evident from the focus on intensity of intervention - of more interest to commissioners than clinicians - this model is rooted in compromise. Ironically though, perhaps the strength of the model lies in this compromise. Based on past experience many are cynical that the kind of support recommended for long-term collection will ever be delivered. However, in this case, there is a direct and practical incentive for commissioners, managers and therefore information departments to provide exactly the kind of support required - namely, they want this information as well. As direct evidence of this in practice, both the local health authority and the NHS information authority continue to directly fund this project, even though it is now focused on providing the kinds of support (e.g. feedback and training) and development (e.g. of intervention categories) requested by clinicians.

\section{Conclusion}

Although demands are made on clinicians to feed current information systems, they appear to get little in return for this effort. While still in its infancy, this model is a good example of how information systems and procedures can evolve to ensure better provision of relevant information to all concerned. This is an essential development if information about the service is to serve its proper purpose - to help improve patient care.

\section{Acknowledgements}

Special thanks to members of all participating clinical teams and members of the project Steering Group, including: Professor Alastair MacDonald (Guy's, King's and St Thomas' School of Medicine, Dentistry and Biomedical Sciences); Mr Mike Denis, Dr Dinshaw Master, Dr Anula Nikapota and Dr David Roy (South London and Maudsley NHS Trust); Dr Richard Carthew (The NHS Information Authority); and Mr Doug Adams and Mr Anil Yogasundram (Lambeth, Southwark and Lewisham Health Authority).

\section{References}

ALLEN, L., BALA, S., CARTHEW, R., et al (1999) Experience and application of HoNOS65+. Psychiatric Bulletin, 23, 203-206.

BURNS, A., BEEVOR, A., LELLIOTT, P., et al (1999) Health of the Nation Outcome Scales for elderly people (HoNOS65+). British Journal of Psychiatry, 174, 424 427.

CARTHEW, R. \& PAGE, R. (1999) Mental health groups: providing the framework to ask the right questions: the development of patient and care groups for Mental Health Services. In The Fourth National Casemix Conference, Casemix into the Millennium. Winchester: The NHS Information Authority.

CLIFFORD, P. (1993) The FACE Project: Final Report to the Department of Health. London: Quality Development Unit.

DEPARTMENT OF HEALTH (1997) The New NHS: Modern, Dependable. London: HMSO.

— (1999) National Service Framework for Mental Health. London: Department of Health.

GLOVER, G., KNIGHT, S., MELZER, D., et al (1997) The development of a new minimum data set for specialist mental health care. HealthTrends, 29, 48-51.

WING, J., CURTIS, R. \& BEEVOR, A. (1996) HoNOS: Brief Report on Research \& Development. London: Royal College of Psychiatrists College Research Unit.

WORLD HEALTH ORGANIZATION (1992) The ICD-10 Classification of Mental and Behavioural Disorders: Clinical Descriptions and Diagnostic Guidelines. Geneva:WHO.

Matthew Broadbent Project Manager, South London and Maudsley NHS Trust, Reay House, 108 Landor Road, Stockwell, London SW9 9NT original papers

\title{
Cognitive-behavioural therapy: a survey of the training, practice and views of Scottish consultant psychiatrists
}

\section{AIMS AND METHOD}

A postal survey of all consultant psychiatrists employed by the NHS in Scotland was performed with the aim of determining the numbers and characteristics of consultant psychiatrists who have received training in cognitive-behavioural therapy (CBT). Additional aims were to ascertain the current practice of CBT, along with general attitudes towards practice and training issues.

\section{RESULTS}

Nine per cent of consultant psychiatrists had received formal training in CBT. An additional $20 \%$ had received informal tuition with supervision of cases. For consultants appointed within the previous five years, $48 \%$ had received the recommended amount of supervised experience. In practice, consultants were unable to devote significant amounts of time to formal CBT but were actively using
CBT techniques and supported the availability of training opportunities.

\section{CLINICAL IMPLICATIONS}

The survey suggests that the current Royal College of Psychiatrists' guidelines do not appear to have been fully implemented for the area surveyed. Further debate is needed to ascertain the exact form that training in CBT should take. 
Cognitive-behavioural therapy (CBT) has been recognised as an effective treatment for many common psychiatric disorders, including depression, anxiety and

original papers somatoform disorders. There is also increasing evidence for its efficacy in patients with psychotic disorders. It remains the most highly researched of all the psychological therapies, making it particularly attractive in the current climate of 'clinical governance' and requirement for evidence-based practice. Although psychology services continue to be the main provider of CBT, it is clear that the potential demand for such a treatment outweighs supply. As a result, increasing numbers of allied mental health professionals (e.g. nurses and occupational therapists) have completed formal training in CBT.

Stern (1993) stressed the importance of CBT training for psychiatrists, particularly the need to make more sophisticated formulations. Stern also stated that without such training psychiatrists are in danger of becoming "therapeutically impotent and therefore less able to lead a multi-disciplinary team". Temple (1999) argued that, in general, psychotherapy training enhances many of the "important aspects of the role of the consultant psychiatrist, especially where the role requires the leadership of a multidisciplinary team". Temple also stated that psychotherapy skills are an important part of the clinical skills and practice in both everyday work and in the effective management of patients and 'self' alike. An important aspect is the ability to assess patients for suitability for a range of psychotherapeutic approaches. The Royal College of Psychiatrists' guidelines for psychiatric training (currently under review) recommend quality CBT training and supervision for all psychiatric trainees (Grant et al, 1993; Royal College of Psychiatrists, 1993). In particular, trainee psychiatrists should have experience of supervised CBT cases during general professional training (senior house officer level). In practice, such supervision appears not to have been incorporated in all training schemes. An unpublished report showed that 5 years after the above guidelines were published, only half of the training schemes in the UK provided adequate training in psychotherapy.

In Scotland formal training in CBT (recognised by the British Association of Behavioural and Cognitive Psychotherapies) is available through two separate courses, one based in Dundee and the other in the South of Scotland (Edinburgh/Glasgow). Both courses have been attended by psychiatrists at various stages in their careers, mainly at specialist registrar and consultant levels. Similar courses are held at other centres throughout the UK. Despite the College recommendations, there still remains uncertainty as to the required degree of training and experience that psychiatrists should receive during training.

In the light of the above, we decided to carry out a postal survey with the following aims:

(a) To determine the numbers and characteristics of consultant psychiatrists who have received training in CBT.

(b) To determine the amount of time that consultant psychiatrists are able to devote to CBT in their NHS clinical practice. (c) To determine the attitudes of consultant psychiatrists towards the practice of and training in CBT.

\section{Method}

In August 1999, we carried out a postal survey of all consultant psychiatrists working within the NHS in Scotland. Names and contact addresses were obtained by cross-referencing a number of sources, including the records from the Royal College of Psychiatrists and information obtained from the personnel officers of relevant NHS primary care trusts.

All consultants identified by the above process were sent a computer-readable questionnaire. The questionnaire asked for details of each consultant's work as well as his or her training in and practice of CBT. Respondants were asked to classify their training according to four categories:

(a) Formal training (an approved qualification in CBTat diploma level or equivalent).

(b) Attendance at brief courses not leading to an approved qualification (not classified further owing to the wide variety of courses available), subdivided according to whether case supervision was received.

(c) Self-directed learning

(d) No training.

Consultants were also asked to rate how much they agreed or disagreed with six statements designed to assess individual attitudes towards CBT, including practice and training issues. After 6 weeks, a reminder was sent to all consultants who had not replied to the initial letter. The questionnaire results were collated and analysed using the Statistical Package for the Social Sciences (SPSS, version 8.0).

\section{Results}

A total of 345 consultants were identified. Two hundred and eighty (81\%) replies were received but 12 questionnaires were returned incomplete. The total number of valid returns was therefore 268 (78\%). Sixty per cent of respondents were male. The majority of returns (58\%) were from consultants working in general adult psychiatry. The other responders came from the following sub-specialities: old age psychiatry $(19 \%)$, child and adolescent psychiatry (11\%), rehabilitation (9\%), learning disabilities (9\%), forensic psychiatry (8\%), substance misuse (8\%), psychotherapy (8\%) and liaison psychiatry (7\%). Many consultants had commitments in more than one speciality.

Nine per cent of consultants indicated that they had received formal training in CBT (ranging from 13\% in those appointed within the past 5 years to $3 \%$ of those who had been consultants for over 15 years). A further $20 \%$ stated that they had received more informal tuition with supervision of cases (from 35\% appointed within the past 5 years to $9 \%$ appointed for more than 15 years). Table 1 provides a breakdown of level of training by sub-speciality. 
Table 1. Numbers and percentage of consultants receiving various levels of cognitive-behavioural therapy training divided by sub-speciality

\begin{tabular}{|c|c|c|c|c|c|c|c|c|c|c|}
\hline & \multicolumn{2}{|c|}{ None } & \multicolumn{2}{|c|}{$\begin{array}{l}\text { Self-directed } \\
\text { learning }\end{array}$} & \multicolumn{2}{|c|}{$\begin{array}{c}\text { Brief courses (with- } \\
\text { out supervision) }\end{array}$} & \multicolumn{2}{|c|}{$\begin{array}{c}\text { Brief courses (with } \\
\text { supervision) }\end{array}$} & \multicolumn{2}{|c|}{ Formal training } \\
\hline & $n$ & $\%$ & $n$ & $\%$ & $n$ & $\%$ & $n$ & $\%$ & $n$ & $\%$ \\
\hline General adult & 43 & 28.3 & 44 & 28.9 & 45 & 29.6 & 32 & 21.1 & 17 & 11.2 \\
\hline Old age psychiatry & 19 & 39.6 & 14 & 29.2 & 13 & 27.1 & 6 & 12.5 & 0 & 0 \\
\hline Learning disabilities & 7 & 35.0 & 5 & 25.0 & 6 & 30.0 & 3 & 15.0 & 0 & 0 \\
\hline Child and adolescent & 6 & 23.0 & 12 & 46.2 & 9 & 34.6 & 5 & 19.2 & 1 & 3.8 \\
\hline Psychotherapy & 5 & 31.5 & 3 & 18.8 & 3 & 18.8 & 5 & 31.3 & 1 & 6.3 \\
\hline Substance misuse & 4 & 22.2 & 7 & 38.9 & 9 & 50.0 & 4 & 22.2 & 1 & 5.6 \\
\hline Liaison psychiatry & 4 & 25.0 & 6 & 37.5 & 3 & 18.8 & 4 & 25.0 & 4 & 25.0 \\
\hline
\end{tabular}

original

papers

Table 2. Consultant's use of cognitive-behavioural therapy (CBT) by sub-speciality

\begin{tabular}{|lcc}
\hline & $\begin{array}{c}\text { Use of CBT } \\
\text { techniques }(\%)\end{array}$ & $\begin{array}{c}\text { Formal CBT } \\
(\%)\end{array}$ \\
\hline General adult & 67.8 & 14.5 \\
Old age psychiatry & 54.2 & 8.3 \\
Learning disabilities & 65 & 5 \\
Child and adolescent & 88.5 & 23.1 \\
Psychotherapy & 37.5 & 12.5 \\
Substance misuse & 83.3 & 16.7 \\
Liaison psychiatry & 81.3 & 31.3 \\
Total & 65.3 & 14.6 \\
\hline
\end{tabular}

Nine per cent of consultants indicated that they had received formal training in CBT (ranging from 13\% in those appointed within the past 5 years to $3 \%$ of those who had been consultants for over 15 years). A further $20 \%$ stated that they had received more informal tuition with supervision of cases (from 35\% appointed within the past 5 years to $9 \%$ appointed for more than 15 years). Table 1 provides a breakdown of level of training by sub-speciality.

A total of 39 consultants (15\%) stated that they carried out formal CBT in their routine NHS practice, 27 of whom (69\%) could only devote 2 hours or less per week to such therapy. Only two consultants indicated that they were able to spend 10 hours or more on formal CBT. A far greater proportion of consultants $(175,65 \%)$ indicated that they integrated general $C B T$ techniques into their routine practice.

These results are presented, according to subspeciality, in Table 2. The highest proportion of consultants practising CBT was found in liaison psychiatry $(n=5$, $31 \%$ ), followed by child and adolescent psychiatry $(n=6$, $23 \%)$. One hundred and two (38\%) consultants stated that they would like to do more CBT in their general everyday work.

Two hundred and forty-five (88\%) consultants indicated that they refer patients for CBT. Two hundred and thirty $(82 \%)$ stated that they would refer to psychology services, but $112(40 \%)$ also stated that they would refer patients to nursing or occupational therapy staff. Only 22 $(8 \%)$ consultants stated that they would refer patients to NHS psychotherapy services for this type of treatment. The average waiting time for CBT after referral was estimated to be 3 months. Responses to the six statements designed to elicit individual attitudes towards CBT, including practice and training issues, are presented in Table 3.

\section{Discussion}

This survey provides an insight into Scottish consultant psychiatrists' views, training and practical use of CBT. The response rate of $78 \%$ suggests that the results of the survey are likely to be representative of the target population.

Table 3. Consultant psychiatrists' attitudes towards cognitive-behavioural therapy (CBT)

\begin{tabular}{|c|c|c|c|c|c|}
\hline & $\begin{array}{l}\text { Strongly agree } \\
\text { (\%) }\end{array}$ & $\begin{array}{l}\text { Agree } \\
(\%)\end{array}$ & $\begin{array}{l}\text { Indifferent } \\
\qquad \%)\end{array}$ & $\begin{array}{l}\text { Disagree } \\
(\%)\end{array}$ & $\begin{array}{c}\text { Strongly disagree } \\
(\%)\end{array}$ \\
\hline CBT is a valuable treatment option & 37 & 58 & 4 & 1 & 0 \\
\hline Resources should be available to provide prompt CBT & 33 & 60 & 4 & 3 & 0 \\
\hline $\begin{array}{l}\text { CBT should only be carried out by individuals with an approved } \\
\text { qualification }\end{array}$ & 13 & 42 & 18 & 26 & 1 \\
\hline CBT is not a good use of time for consultant psychiatrists & 8 & 25 & 23 & 39 & 5 \\
\hline $\begin{array}{l}\text { Training in CBT should be made available to all trainee } \\
\text { psychiatrists }\end{array}$ & 33 & 54 & 7 & 4 & 1 \\
\hline $\begin{array}{l}\text { Training in CBT should be made available to all consultant } \\
\text { psychiatrists }\end{array}$ & 18 & 59 & 19 & 4 & 1 \\
\hline
\end{tabular}


Our results suggest a high level of support for CBT. Ninety-five per cent of psychiatrists considered it to be a valuable treatment option that should be made readily available, although over half of all consultants thought that it should be carried out only by appropriately qualified staff. However, only $48 \%$ of consultants appointed within the past 5 years appeared to have received the recommended level of supervised training, confirming a report by Gibb and Temple (1998) that local training schemes have been unable to adhere to College guidelines. It is, of course, possible that some of the surveyed consultants completed their basic training before College recommendations were issued in 1993.

Sixty-five per cent of the surveyed consultants indicated that they use CBT techniques in their general NHS work, although a much smaller proportion $(15 \%)$ appeared to practise formal CBT. The practice of formal CBT appeared to vary according to sub-speciality and seemed particularly high in the sub-specialities of liaison and child and adolescent psychiatry. This may relate to the perceived importance of CBT in the management of patients in these areas. Although the current requirements for higher training in psychotherapy require at least 100 hours of supervised practice in CBT, with 700 hours if training primarily in CBT (Royal College of Psychiatrists, 1998), only a small proportion of consultant psychotherapists practised CBT on a regular basis (12.5\%). Psychodynamic psychotherapy continues, therefore, to be the mainstay of NHS consultant-led psychotherapy services.

Forty-four per cent of respondents considered that the practice of CBT constitutes good use of consultant time, whereas a third felt that it was not. The vast majority, however, supported the availability of CBT training for both consultants and psychiatric trainees. However, few consultants seemed able to devote a significant amount of time to CBT in their routine clinical practice. This raises the important question concerning the kind of CBT training that psychiatrists should receive and whether more extensive training, at least on a larger scale, constitutes best value for money.

The vast majority ( $82 \%$ ) of consultants stated that they refer patients to psychology services for CBT, with a significant proportion (40\%) also referring patients to nursing or occupational therapy staff. These mental health professionals have increasingly taken on the role of providing psychological therapies, particularly in community mental health settings. What, therefore, should be the consultant's role in the delivery of formal psychotherapy? Temple (1999) has argued that limiting the psychiatrist's role to the diagnostic assessment and drug treatment of patients with serious mental illness would be detrimental to overall patient care because the psychiatrist "still has the broadest training in the diverse aspects affecting mental health". The delivery of effective psychological treatments by nursing or occupational therapy staff is, however, an attractive and cost-effective option, provided that regular ongoing supervision is made available to such staff. We suggest that there is a need for wider debate on the issue of which professionals, in a variety of psychiatric settings, are best placed to practise CBT.

Like other studies of this nature, this survey has a number of potential weaknesses. Although our response rate of $78 \%$ is a respectable return for surveys of this kind, non-responders present a possible bias because this group of consultants might have been less supportive of CBT. Also, responders were given limited opportunity to elaborate on their answers because the questionnaire was designed to be brief and easily completed in a few minutes. In particular, the question regarding previous training in CBT could have misclassified consultants who had received case supervision but had not attended any particular training course. We do feel, however, that the results reveal a useful 'snapshot' picture of training, current practice and views of CBT in our target group. It would be interesting to see whether a similar survey, carried out in the future, will reveal change.

\section{Conclusions}

Most Scottish consultant psychiatrists regard CBT as a valuable treatment option. Recently appointed consultants (within the past 5 years) have had higher levels of exposure to this form of treatment but in practice consultants are unable to devote significant amounts of time to its formal application. Many consultants indicated, however, that they incorporate CBT techniques into their everyday practice. There was a widespread view that training in CBT should be made available to both consultants and trainees, although given the current restraints on consultants' time the question of which professional group(s) within the multi-disciplinary team should receive more extensive training deserves further attention.

\section{References}

GRANT, S., HOLMES, J. \& WATSON, J. (1993) Guidelines for psychotherapy training as part of general professional psychiatric training. Psychiatric Bulletin, 17, 695-698.

\section{ROYAL COLLEGE OF PSYCHIATRISTS}

(1993) Guidelines for Psychotherapy Training as Part of General Professional PsychiatricTraining. Council Report

CR27. London: Royal College of Psychiatrists.
OP43. London: Royal College of Psychiatrists.

STERN, R. (1993) Behavioural-cognitive psychotherapy training for psychiatrists. Psychiatric Bulletin, 17, $1-4$.

TEMPLE, N. (1999) Should consultant psychiatrists be trained in psychotherapy? Advances in Psychiatric Treatment, 5, 288-295.
—(1998) Higher Specialist Training

Handbook. Occasional Paper

*Peter Le Fevre Consultant Psychiatrist, Rainer Goldbeck Consultant Psychiatrist, Clerkseat Building, Royal Cornhill Hospital, Aberdeen, AB25 2ZH (tel: 01224 557 201; fax: 01224557433 ) 